\title{
PCR detection of Streptococcus mutans and Streptococcus sobrinus in plaque samples from Mongolian mother-child pairs
}

\author{
Mashbaljir Soyolmaa ${ }^{1, *}$, Luvsan Munguntsetseg ${ }^{1}$, Munkh-Od Sharkhuu ${ }^{1}$, \\ Mizuho Nishino ${ }^{2}$ and Ulamnemekh Hulan ${ }^{1}$ \\ ${ }^{1}$ School of Dentistry, Health Sciences University of Mongolia \\ Choidog 3, Ulaanbaatar-48, P.O.B. 111, MONGOLIA \\ 2 The University of Tokushima \\ 2-24 Shinkura-cho, Tokushima 770-8501, JAPAN
}

\begin{abstract}
Early childhood caries results in a considerable burden of pain and suffering as well as poorer general health. Streptococcus mutans (serotypes $c, e$ and $f$ ) and Streptococcus sobrinus (serotype $d$ and $g$ ) are the species closely associated with dental caries. The exact age at which their colonization occurs in children is controversial. The objective of this study was to detect S. mutans and S. sobrinus in plaque samples of Mongolian mother-child pairs by PCR and to compare their presence with the caries status. Dental examination and caries risk assessment using the Cariostat ${ }^{\circledR}$ carried out on 320 children aged 6-30 months and their mothers. The presence of S. mutans and S. sobrinus was checked by PCR. The caries prevalence and DEFT scores of mothers enrolled in the present study were $98 \%$ and $11.5 \pm 0.7$, respectively. In children, the prevalence and deft scores of the 6-18-month-olds were $29 \%$ and $1.3 \pm 0.2$ while those of the 19-30-month-olds were 59\% and $3.4 \pm 0.4$ correspondingly. Twenty nine percent of the 6-18-months old children of high-risk mothers and $53.1 \%$ of the $19-30$-months old children of high-risk mothers had high caries risk $(P<0.001)$. There was a statistically significant correlation between caries risk of 19-30 month-old children and their mothers $(P<0.001)$. In mothers, the prevalence of S. mutans and S. sobrinus was $79 \%$ and 33\%, respectively; $54 \%$ harbored S. mutans alone, $8 \%$ harbored S. sobrinus alone, 25\% harbored both strains. In children, $45 \%$ were positive for S. mutans alone, $9 \%$ were positive for S. sobrinus alone, $18 \%$ were positive for both strains. Either or both strains were detected in $67.3 \%$ of 6-18-months old children and $76.5 \%$ of 19-30-months old children. In conclusion, our results showed that S. mutans and/or S. sobrinus first colonized infants' teeth from 6-18 months, and the colonization increased with increasing age, so that by 30 months of age, $76.5 \%$ of children harbored the bacteria.
\end{abstract}

Key words

Caries activity test, Caries risk, PCR, S. mutans, S. sobrinus

\section{Introduction}

Early childhood caries results in a considerable burden of pain and suffering as well as poorer general health ${ }^{1}$. The principal causative agents of dental caries are a group of microorganisms collectively referred to as mutans streptococci. Mutans

\footnotetext{
* Correspondence to: Mashbaljir Soyolmaa

E-mail: soyoloom_71@yahoo.com

Received on April 5, 2011; Accepted on June 30, 2011
}

streptococci possess a number of phenotypic traits such as the synthesis of extracellular polysaccharides, acid production, aciduricity, intracellular polysaccharides synthesis and endodextranase production, which are fundamental to their cariogenicity. Among them, Streptococcus mutans (serotypes $c, e$ and $f$ ) and Streptococcus sobrinus (serotype $d$ and $g$ ) are the species closely associated with human dental caries $^{2-8)}$.

Serotyping, bacteriocin typing, and genetic 
studies have shown that mutans streptococci strains are commonly transferred from a mother to her infant. The exact age at which mutans streptococci colonization occurs in children is controversial ${ }^{9-12}$. Mutans streptococci colonize infants' teeth at 19-31 months of age, a period described by Caufield et al. as the "window of infectivity"13-15). However, recently it has been reported that $S$. mutans has been found in predentate infants ${ }^{16,17}$. The earlier colonization occurs, the greater the risk of caries development in both deciduous and permanent dentition. Thus, it is very important to assess caries risk of children early in life.

Caries activity testing is very effective in determining the caries risk of children. The Cariostat ${ }^{\circledR}$ test developed by Shimono is a colorimetric test based on the acidogenic properties of dental plaque microorganisms. The Cariostat liquid medium contains $20 \%$ of sucrose and $\mathrm{pH}$ indicators. After incubation of 48 hours at $37^{\circ} \mathrm{C}$, scoring is done according to the color changes of test ampoules ${ }^{12,18,19)}$.

Recent developments in the field of molecular biology have provided a more sensitive means of detection of cariogenic bacteria. DNA assays can be used to identify closely related species that are difficult to differentiate by traditional, culture-based approaches ${ }^{20-23)}$.

The objective of this study was to detect S. mutans and S. sobrinus in Cariostat-inoculated plaque samples of Mongolian mother-child pairs by PCR and to compare their presence with the caries status.

\section{Materials and Methods}

\section{Subject selection}

The study population consisted of 320 mother-child pairs attending the Health Centers of Songinokhairkhan and Bayangol districts of Ulaanbaatar city. The ages of the children ranged from 6 to 30 months. The children were grouped by age range: 6-18 $(n=160)$ and 19-30 month-old groups $(n=160)$. All children had at least two teeth present during the examination. The mother's average age was $29.3 \pm 5.59$ years. An informed consent was obtained from all parents for the examination and sampling procedures.

\section{Oral examination}

A dental examination was done using a mouth mirror and explorer under natural light. The WHO caries diagnostic criteria were used for determining the deft (decayed, extracted, filled) index.

\section{Plaque sampling and caries risk assessment using Cariostat test}

For each mother-child pairs plaque was collected by the swabbing from the buccal surfaces of the maxillary teeth using a sterile cotton swab. Each plaque sample was put into the Cariostat medium (Morita Co., Japan) and incubated at $37^{\circ} \mathrm{C}$ for 48 hours. After incubation the colorimetric changes were classified into seven grades using the original four grade standard color sample. A score of " 0 " shows a low caries risk while "3.0" shows a high caries risk. The subjects with Cariostat scores of 0 to 1 ( $\mathrm{pH} 7.2-5.4)$ were placed in the low-risk group, and those with Cariostat scores of 1.5-3 ( $\mathrm{pH}$ 5.0-3.8) in the high-risk group. This was done to establish caries risk grouping of the children and their mothers ${ }^{12,24,25)}$. The Cariostat ampoules were shown to the children and mothers in order to give them a visual aid regarding their caries risk. Then, these Cariostat-inoculated plaque samples were further used for the following experiments.

\section{Experimental procedures and PCR}

The plaque samples cultured in Cariostat liquid medium from 100 mother-child pairs (200 samples) were randomly selected. The Cariostat ampoules containing the samples were vortexed (Vortex genie2) to dislodge bacteria attached to cotton swab. Then $1 \mathrm{~m} l$ of the sample solution was transferred into a mini centrifuge tube, and harvested by centrifugation at 7,500 rpm for 15 minutes. The supernatant was discarded carefully. Bacterial DNA extraction was performed using the GenElute ${ }^{\mathrm{TM}}$ Bacterial Genomic DNA Kit's protocol for purification of DNA from Gram-positive bacteria.

S. mutans ATCC 25175 and S. sobrinus ATCC 33478 were used as reference strains. The primer pairs SD1/SD2 and SOF14/SOR1623 were employed ${ }^{20-23)}$. PCR amplification was performed in a reaction mixture $(40 \mu l)$ that contained $24 \mu l$ of distilled water, $4 \mu l$ of 10X PCR buffer solution, $4 \mu l$ of dNTPs, $0.5 \mu l$ of each primer, $1 \mu l$ of Taq (AmpliTaq ${ }^{\circledR}$ DNA Polymerase, Roche, Germany), and $5 \mu l$ of the template DNA. PCR products were analyzed by gel electrophoresis in a $1 \%$ agarose gel containing ethidium bromide (a final concentration $0.5 \mathrm{ug} / \mathrm{mL}$ ) and visualized by ultraviolet light. The presence or absence of bands was noted and compared within 


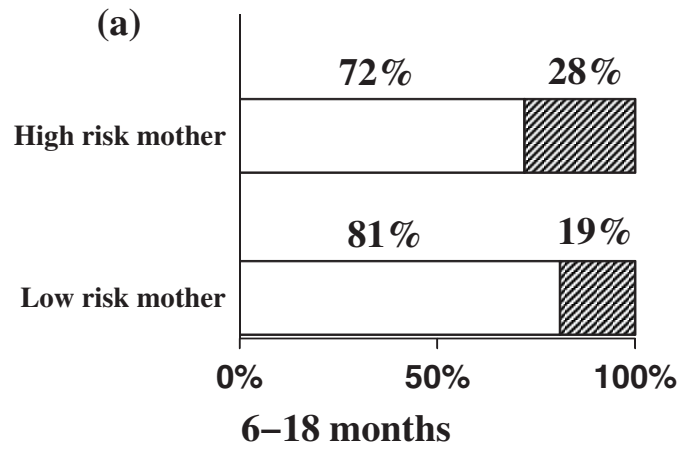

Low risk child

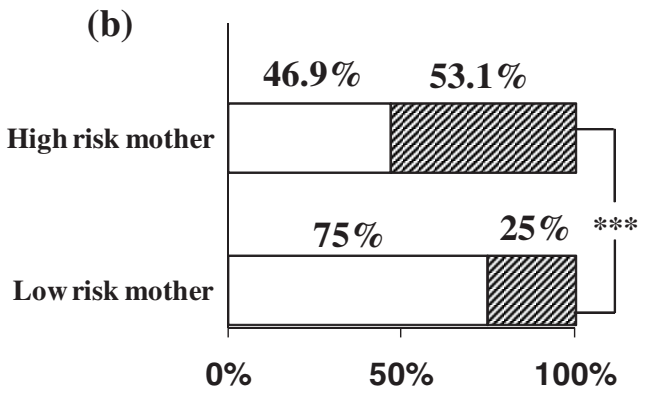

19-30 months

High risk child

Fig. 1 Caries risk for mother-child pairs by age group of children ((a) 6-18 months olds, (b) 19-30 months olds)

(a)

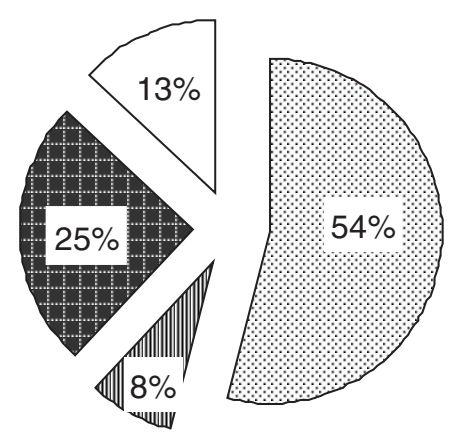

S.mutans (b)

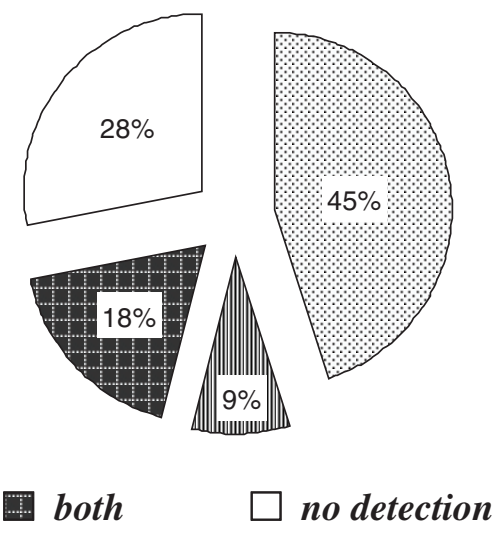

Fig. 2 The prevalence of mutans streptococci in mothers (a) and their children (b)

each mother-child pair ${ }^{20-22)}$.

\section{Statistical analysis}

Data were processed with SPSS 11.5 software. Relationships between caries risk and band detection in mother-child pairs, and differences in caries experience were evaluated statistically using Pearson's correlation coefficient, Chi-square test, and ANOVA.

\section{Results}

The caries prevalence and DEFT scores of mothers enrolled in the present study were $98 \%$ and 11.5 \pm 0.7 , respectively. In children, the prevalence and deft scores of the 6-18 month-olds were $29 \%$ and $1.3 \pm 0.2$, respectively, while those of the 19-30 month-olds were $59 \%$ and $3.4 \pm 0.4$, correspond- ingly. The caries prevalence and deft scores were significantly higher in the 19-30 month-old group compared to the 6-18-month-old group $(P<0.001)$.

As assessed using Cariostat test, $62.2 \%$ of mothers had high caries risk, while $37.8 \%$ of them had low caries risk. $24.1 \%$ of the children aged 6-18 months, and $47.2 \%$ of the children aged 19-30 months were at high risk of developing caries $(P<0.001)$.

Figure 1 presents the relationship between caries risk for mother-child pairs. A statistically significant correlation was seen between children's caries risk and their mothers, for children whose age range was 19-30 months $(P<0.001)$. However, no significant difference was seen between 6-18 months children and their mothers probably due to the small number of erupted teeth.

Figure $2 \mathrm{a}$ and $2 \mathrm{~b}$ show the prevalence of 


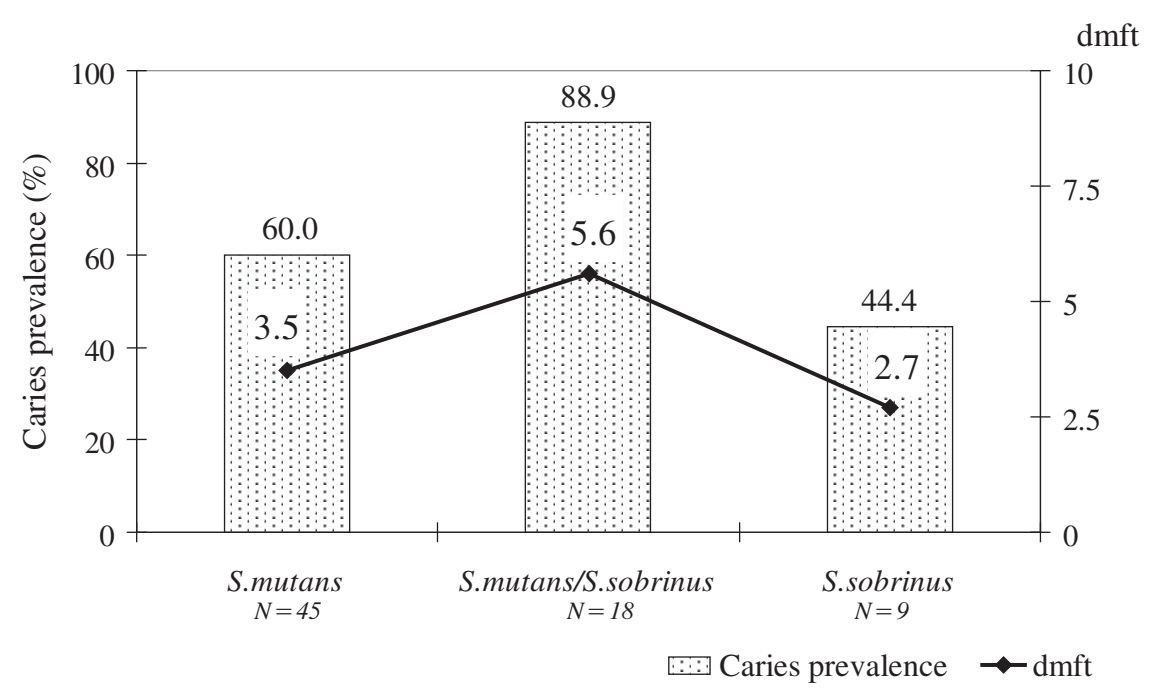

Fig. 3 Caries status and presence of mutans streptococci in children

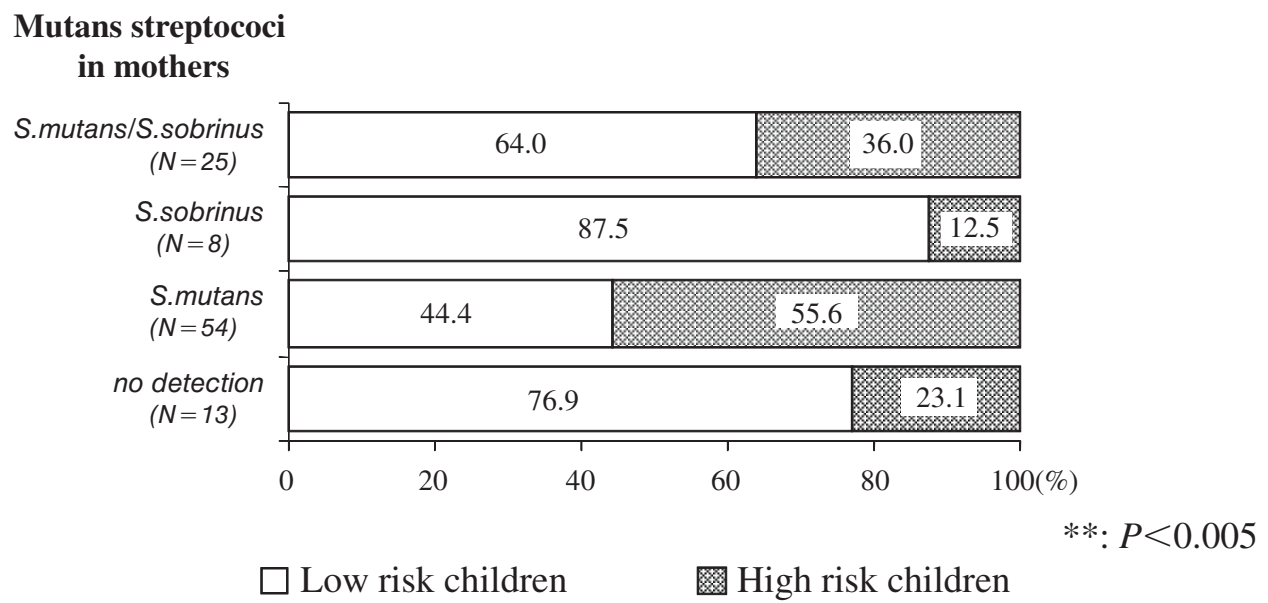

Fig. 4 Presence of cariogenic bacteria in mothers and caries risk levels of their children

S. mutans and S. sobrinus. In mothers, the prevalence of S. mutans and S. sobrinus was $79 \%$ and $33 \%$, respectively; 54\% harbored S. mutans alone, $8 \%$ harbored S. sobrinus alone, $25 \%$ harbored both strains, whereas $13 \%$ were negative for both strains. In children, $45 \%$ were positive for $S$. mutans alone, $9 \%$ were positive for S. sobrinus alone, $18 \%$ were positive for both strains.

Children harboring both $S$. mutans and S. sobrinus $(88.9 \%)$ have a significantly higher prevalence of dental caries than those with S. mutans $(60 \%)$ or S. sobrinus $(44.4 \%)$ alone $(P<0.01)$. The mean deft of children harbouring $S$. mutans was $3.5 \pm 0.59$, that of children with S. sobrinus $2.7 \pm 1.56$ and that of children with both strains was $5.6 \pm 1.10(P<0.05$,
Fig. 3).

Moreover, a significant correlation was found between the presence of $S$. mutans or both strains in mothers and the caries risk of children $(P<0.05)$. The caries risk was low in $76.9 \%$ of children of mothers negative for both $S$. mutans and $S$. sobrinus, and in $87.5 \%$ of children of mothers positive for $S$. sobrinus. Whereas, most of the children of mothers positive for $S$. mutans alone and positive for both strains had high caries risk ( $P \leq 0.05$, Fig. 4$)$.

\section{Discussion}

Several studies have shown that preventive measures against the early colonization of mutans streptococci 
in children are effective in prevention of later dental caries development ${ }^{9,11,26)}$. Thus, this study was done to investigate the relationship between the presence of mutans streptococci in dental plaque samples obtained from Mongolian mother-child pairs and their caries status.

The main finding of our study was a relationship between caries risk of mothers and their children, showing that a high risk of dental caries in mothers leads to a high risk of developing carious lesions in their children as they become older. Twenty-eight percent of the 6-18-months old children of high-risk mothers and $53.1 \%$ of the $19-30$-months old children of high-risk mothers had high caries risk $(P<0.001)$. There was a statistically significant correlation between caries risk of 19-30 month-old children and their mothers $(P<0.001)$. Also, a significant positive correlation has been found between decayed teeth in mothers and decayed teeth in their children. However, no significant correlation has been seen between caries risk of 6-18-month-olds and their mothers. The lower dental caries risk and caries status in 6-18-month-olds was probably, due to the small number of erupted teeth, dietary and feeding habits, and caregiver behavior at the time of examination. This finding was also in line with the findings of Rodis et al. ${ }^{12)}$ Furthermore, Fujiwara et al. found that the concentration of mutans streptococci correlated with the number of erupted teeth, and the concentration of mutans streptococci was more closely correlated to the caries prevalence of the next year than that of the year when the salivary concentration of mutans streptococci was first evaluated $^{27)}$.

The important finding of this study was that either or both strains were detected in $67.3 \%$ of 6-18-months old children and $76.5 \%$ of $19-30$ months old children. Caufield and his colleagues established a discrete "window of infectivity" period from 19-31 months of age ${ }^{13-15)}$. However, along with findings of other studies ${ }^{16,17)}$, the results of this study suggest that children may be colonized by S. mutans before the "window of infectivity" opens.

The results of the present study suggest that there is a tendency for mothers and children to share similar susceptibility to S. mutans and S. sobrinus colonization. In mothers, the prevalence of $S$. mutans and S. sobrinus was $79 \%$ and $33 \%$, respectively; $54 \%$ harbored S. mutans alone, $8 \%$ harbored S. sobrinus alone, 25\% harbored both strains. In children, $45 \%$ were positive for $S$. mutans alone, $9 \%$ were positive for S. sobrinus alone, $18 \%$ were positive for both strains.

The present PCR findings also confirmed that children positive for both S. mutans and S. sobrinus had significantly higher caries prevalence and caries risk as compared to those positive for $S$. mutans alone which agrees with the results of other surveys ${ }^{26,28)}$.

In conclusion, our results showed that $S$. mutans and/or S. sobrinus colonization increased with increasing age, so that by 30 months of age, $76.5 \%$ of children harbored the bacteria. These data would be relevant for development of preventive strategies of early childhood caries in Mongolia.

\section{Acknowledgements}

We thank Professor Tsutomu Shimono of Okayama University Graduate School of Medicine, Dentistry and Pharmaceutical Sciences and Dr. Bazar Oyuntsetseg of School of Dentistry, HSUM for providing us the Cariostat tests.

\section{References}

1) Acs, G., Shulman, M., Nj, M.W. and Chussid, S.: The effect of dental rehabilitation on the body weight of children with early childhood caries. Pediatr Dent 21: 109-113, 1999.

2) Hamada, S. and Slade, H.D.: Biology, immunology, and cariogenicity of Streptococcus mutans. Microbiol Rev 44 (2): 331-384, 1980.

3) Hamada, S., Koga, T. and Ooshima, T.: Virulence factors of Streptococcus mutans and dental caries prevention. J Dent Res 83 (3): 407-411, 1984.

4) Hamada, S., Horikoshi, T., Minami, T., Okahashi, N. and Koga, T.: Purification and Characterization of cell-associated glucosyltransferase synthesizing water-insoluble glucan from serotype c Streptococcus mutans. J Gen Microbiol 135: 335-344, 1989.

5) Marcotte, H. and Lavoie, M.C.: Oral microbial ecology and the role of salivary immunoglobulin A. Microbiol Mol Biol Rev 62 (1): 71-109, 1998.

6) Tanzer, J.M.: On changing the cariogenic chemistry of coronal plaque. J Dent Res 68 (Special Issue): 1576-1587, 1989.

7) Tanzer, J.M.: Microbiology of dental caries. In: Contemporary Oral Microbiology and Immunology (Slots, J. and Taubman, M.A. eds.) Mosby-Year Book, St. Louis, MO, 1992, pp.377-424.

8) Van Houte, J.: Bacterial specificity in the etiology of dental caries. Int Dent J 30 (4): 305-326, 1980.

9) Alaluusua, S. and Renkonen, O.V.: Streptococcus mutans establishment and dental caries experience in children from 2 to 4 years old. Scand J Dent Res 91: 453-457, 1983.

10) Mattos-Graner, R.O., Li, Y., Caufield, P.W., Duncan, 
M. and Smith, D.: Genotypic diversity of mutans streptococci in Brazilian nursery children suggests horizontal transmission. J Clin Microbiol 39: 23132316, 2000.

11) Wan, A.K.L., Seow, W.K., Purdie, D.M., Bird, P.S., Walsh, L.J. and Tudehope, D.I.: A longitudinal study of Streptococcus mutans colonization in infants after tooth eruption. J Dent Res 82: 504-508, 2006.

12) Rodis, O.M.M., Okazaki, Y., Kariya, N., Ji, Y., Kanao, A., Hayashi, M., Matsumura, S. and Shimono, T.: Presence of Streptococcus mutans or Streptococcus sobrinus in Cariostat ${ }^{\circledR}$-inoculated plague samples from Japanese mother-child pairs. Ped Dent J 15 (1): 98-102, 2005.

13) Caufeld, P.W., Cutter, G.R. and Dasanayake, A.P.: Initial acquisition of mutans streptococci infections in infants: Evidence for a discrete window of infectivity. J Dent Res 72: 37-45, 1993.

14) Caufeld, P.W., Cutter, G.R. and Dasanayake, A.P.: Initial acquisition mutans streptococci by infants from their mothers. J Dent Res 74: 681-685, 1993.

15) Caufield, P.W. and Hardin, J.M.: Natural history of Streptococcus sanguinis in the oral cavity of infants: evidence for a discrete window of infectivity. Infect Immun 68: 4018-4023, 2000.

16) Wan, A.K.L., Seow, K., Purdle, P.S., Walsh, L.J., Bird, P.S., Tudehope, D.L. and Ass Purdle, D.M.: Association of Streptococcus mutans and oral developmental nodules in predentate infants. J Dent Res 80: 2060-2065, 2001.

17) Wan, A.K.L., Seow, W.K., Purdie, D.M., Bird, P.S., Walsh, L.J. and Tudehope, D.I.: Oral colonization of Streptococcus mutans in six-month-old predentate infants. J Dent Res 80: 2060-2065, 2003.

18) Shimono, T. and Sobue, S.: A new colorimetric caries activity test. Dent Outlook 43 (6): 829-835, 1974. (in Japanese)

19) Rodis, O.M.M., Okazaki, Y., Ji, Y., Matsumura, S. and Shimono, T.: Comparison of plaque samples and saliva samples using the CAT21 Test ${ }^{\circledR}$ (Cariostat method). Ped Dent J 15 (1): 6-9, 2005.

20) Ida, H., Igarashi, T., Yamamoto, A., Goto, N. and Sasa, R.: A DNA probe specific to Streptococcus sobrinus. Oral Microbial Immunol 14: 233-237, 1999.

21) Igarashi, T., Yamamoto, A. and Goto, N.: Direct detection of Streptococcus mutans in human dental plaque by Polymerase chain reaction. Oral Microbiol Immunol 11: 294-298, 1996.

22) Igarashi, T., Yamamoto, A. and Goto, N.: PCR for detection and identification of Streptococcus sobrinus. J Med Microbiol 49: 1069-1074, 2000.

23) Rodis, O.M.M., Matsumura, S., Kariya, N., Ji, Y. and Shimono, T.: Viability of the Cariostat ${ }^{\circledR}$ medium as a source of DNA for further analysis through polymerase chain reaction. Ped Dent J 15 (1): 103$109,2005$.

24) Oyuntsetseg, B., Okazaki, Y., Hori, M., Rodis, O.M.M., Matsumura, S. and Shimono, T.: Caries activity test in Mongolian and Japanese children. Ped Dent J 14: 61-67, 2004.

25) Oyuntsetseg, B., Okazaki, Y. and Shimono, T.: Associations between caries activity, salivary buffer tests and caries increment in Mongolian children. Ped Dent J 15 (1): 110-114, 2005.

26) Köhler, B., Andreen, J. and Jonsson, B.: The earlier the colonization by mutans streptococci, the higher the caries prevalence at 4 years of age. Oral Microbiol Immunol 3: 14-17, 1988.

27) Fujiwara, T., Sasada, E., Mima, N. and Ooshima, T.: Caries prevalence and salivary mutans streptococci in 0-2-year-old children of Japan. Community Dent Oral Epidemiol 19 (3): 151-154, 1991.

28) Okada, M., Soda, Y., Hayashi, F., Doi, T., Suzuki, Miura, K. and Kozai, K.: PCR detection of Streptococcus mutans and S. sobrinus in dental plaque samples from Japanese pre-school children. J Med Microbiol 51: 443-447, 2002. 